\title{
Mathematical Models on Water Scarcity Prediction, Influencing Factors Analysis and Water Transfer
}

\author{
Xin Zheng \\ Department of Electrical Engineering, North China Electric Power University, Baoding 07100, China
}

15733228927@163.com

Keywords: water scarcity; regression model; grey relational model; VPR

\begin{abstract}
Predicting and modeling the water scarcity condition is a complex problem. In this article, the regression model predicting the water demand and supply and the gray relational model analyzing the factors of water scarcity are proposed. Take Henan for example, Henan is heavily lack for water. To remit the situation of water scarcity, VPR (Vehicle Routing Problem) model can help find a best plan to transport water from Danjiangkou reservoir to Henan.
\end{abstract}

\section{Introduction}

As it's known to all, water is the source of life, and the soul of nature. Besides, water plays a vital role in national economic development and living quality. Human require water for industrial, agricultural, and residential purposes. However, there is little water that can be directly used, in spite of the huge amount. According to the statistics released by the United Nations, there are 1.6 billion people (one quarter of the world's population) facing water scarcity. What's worse, the water pollution, the climate changes, and the population increase make the matter even worse.

To tackle the problems of water scarcity, there are three models proposed in this paper. The regression model performs well in predicting the water supply and demand. Besides, the gray relational model can analyze the link of complex factors. Finally, VPR (Vehicle Routing Problem) is designed to project the plan of water movement. Henan is chosen to test these models.

\section{The Regression Model: Forecast Water Demand and Supply}

The factors effecting the water demand and supply can be classified into environment and social elements. Before we settle models to forecast the water demand and supply, we should calculate the data of these indispensable factors. In order to show their relationship with the water demand and supply, the Fig. 1 is as below.

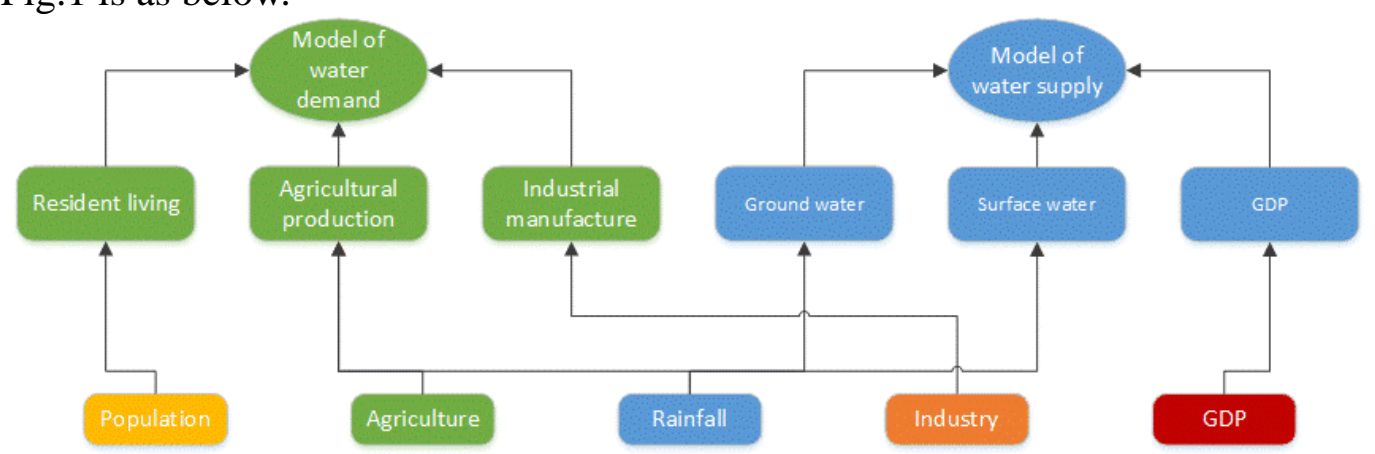

Fig.1 The relationship of factors

In this article, we use logistic model to predict the population (P), and use non-seasonal ARIMA model to predict the rainfall $(R)$, and use grey forecasting model to predict industrial value $\left(V_{I}\right)$ and agricultural value $\left(\mathrm{V}_{\mathrm{A}}\right)$ and gross domestic product (GDP) [1, 2].

Water demand can be divided into three elements: residential living $\left(D_{R}\right)$, agricultural production $\left(D_{A}\right)$, and industrial manufacture $\left(D_{I}\right)$.

Water consumption per capita (C) is assumed to be constant to simplify the model. With the change of the population, the amount of water demand also changes. 


$$
D_{R}=P \times C
$$

Rainfall and agricultural value have closely relationship with $\mathrm{D}_{\mathrm{A}}$, and industrial value has an important effect on $\mathrm{D}_{\mathrm{I}}[3,4]$. So I get the regression equations as below:

$$
\begin{gathered}
\ln D_{A}=d_{0}+d_{1} \ln V_{A}+d_{2} \ln R \\
\ln D_{I}=d_{0}+d_{1} \ln V_{I}
\end{gathered}
$$

The factors impacting the amount supply water of one year are not only environment elements (e.g. surface water, ground water, and other water resources), but also social elements like GDP. However, in consideration of the difficulty of water use, other water resources are hard to transform to clean water to use. So we only take the amount of ground water resources $\left(\mathrm{x}_{1}\right)$ and surface water resources $\left(\mathrm{x}_{2}\right)$ along with GDP into account. The regression equation is as below:

$$
\ln S=d_{0}+d_{1} \ln x_{1}+\ln x_{2}+\ln G D P
$$

Substitute the value of all elements into eq.1 - eq.4, we get the unknown coefficients [5]. Then we can predict the water demand and supply.

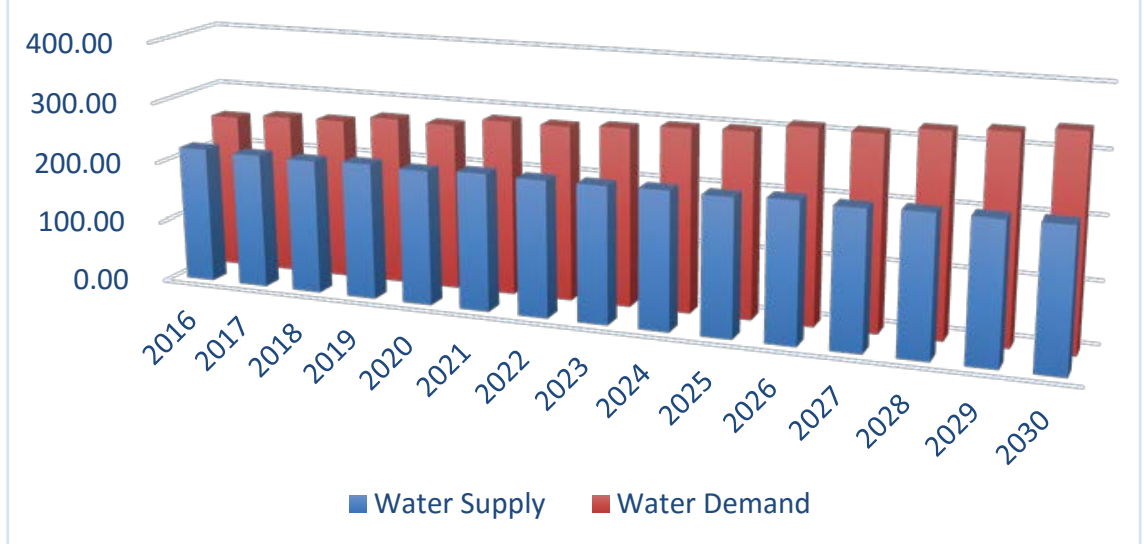

Fig. 2 Compare of water supply and water demand in Henan

From the Fig.2, we can obviously find Henan will experience water scarcity in 2016 2030, and as time goes by the scarcity will become more terrible. The water can be supplied has little fluctuation and trends to be a constant. On the contrary, the water supply grows steadily, which results in the scarcity of water in Henan. And we need to think about plans to get more water, otherwise the growth of Henan economic and the quality of residents will experience great trouble.

\section{The Gray Relational Model: Analyze the Factors of Water Scarcity}

We do data pre-processing work at first, different ways to different kind of data. Then we choose the water supply as the reference sequence $\mathrm{x}_{0}=\left\{\mathrm{x}_{0}(\mathrm{k}) \mid \mathrm{k}=1,2, \ldots \mathrm{n}\right\}=\left\{\mathrm{x}_{0}(1), \mathrm{x}_{1}(2), \cdots, \mathrm{x}_{3}(\mathrm{n})\right\}$, where $\mathrm{k}$ stands for time. Assume there are $\mathrm{m}$ comparison sequences as $\mathrm{x}_{\mathrm{i}}=\left\{\mathrm{x}_{\mathrm{i}}(\mathrm{k}) \mid \mathrm{k}=\right.$ $1,2, \ldots n\}=\left\{x_{i}(1), x_{i}(2), \cdots, x_{i}(n)\right\}, i=1,2, \cdots, m$.[6] We define the correlation coefficient as below.

$$
\xi_{i}(k)=\frac{\min _{s} \min _{t}\left|x_{0}(t)-x_{s}(t)\right|+\rho_{s}^{\max \max _{t}}\left|x_{0}(t)-x_{s}(t)\right|}{\left|x_{0}(t)-x_{i}(t)\right|+\rho_{s}^{\max } \max _{t}\left|x_{0}(t)-x_{s}(t)\right|}
$$

In which $\xi_{i}(k)$ is the correlation coefficient of $x_{i}$ to $x_{0}$, and $\rho \in[0,1]$ is resolution coefficient. Finally we can get the correlation degree of $x_{i}$ to $x_{0}$ in the following.

$$
r_{i}=\frac{1}{n} \sum_{k=1}^{n} \xi_{i}(k)
$$

Using the grey relational model, we get the correlation degree of each factors between with water supply in Henan as the Tab.1. 
Tab.1 The correlation degree of factors between with water supply

\begin{tabular}{cccc}
\hline Environment factors & $\xi$ & Society factors & $\Xi$ \\
\hline Rainfall & 0.3744 & Added industry value & 0.3409 \\
Surface water & 0.9246 & Personal consumption & 0.5085 \\
Ground water & 0.8722 & Industry pollution & 0.9976 \\
Other water resources & 0.5719 & Living pollution & 0.9987 \\
& & Water storage & 0.9997 \\
\hline
\end{tabular}

It shows that as for environment factors the amount of the surface water and ground water is connected closely to the water supply in Henan. Besides as for society factors, the water pollution of industry and living, as well as water storage have great impact on the water supply too. It shows the situation of water pollution is pretty serious in Henan, which reduces the water supply. And the relationship of water storage and water supply tells the importance of water storage.

\section{The Vehicle Routing Problem Model: Transport Water}

We choose the Danjiangkou reservoir as the water source to supply water to the cities in Henan. We assume the demand water of city $i$ is $g_{i}$, the facility of water movement from the source can carry water $\mathrm{q}_{\mathrm{n}}$, which passes $\mathrm{n}$ cities, and finally go back to the source. Our goal is to arrange the water movement routes reasonably to cover the demand of all cities and make sure the routes is shortest. So we build the VRP model with the goal of least routes distance as below [7].

$$
\left\{\begin{array}{c}
\min D=\sum_{i=0}^{h} \sum_{j=0}^{h} \sum_{s=1}^{k} c_{i j} x_{i j s} \\
\sum_{i=0}^{h} x_{i j s}=y_{i s}, j=1,2, \cdots, h, \forall s \\
\sum_{j=0}^{h} x_{i j s}=y_{i s}, i=1,2, \cdots, h, \forall s \\
\sum_{i=0}^{h} g_{i} y_{i s} \leq q_{s}, \forall s \\
\sum_{s=0}^{k} y_{i s}= \begin{cases}1 & i=1,2, \cdots, h \\
k & i=0\end{cases}
\end{array}\right.
$$

Where $c_{i j}$ stands for the cost of traffic from city $i$ to city $j . x_{i j s}$ stands for the traffic, when facility $\mathrm{s}$ travel from $\mathrm{i}$ to $\mathrm{j}, \mathrm{x}_{\mathrm{ijs}}$ is equal to 1 , otherwise it is equal to $0 . \mathrm{y}_{\mathrm{is}}$ shows the task of city $\mathrm{i}$ water supply is accomplished by facility $\mathrm{s}$, if it happens, it is 1 . If not, it is 0 . $\mathrm{q}_{\mathrm{s}}$ represents the maximum of water carrying capacity of the facility s. Substitute the data to the VRP model, after 100 iterations in GA (Genetic Algorithm) [8]. We obtain the order and the ratios as below.

Tab.2 The order and the ratios of water transport

\begin{tabular}{cccc|cccc}
\hline Number & City & Ratio & Order & Number & City & Ratio & Order \\
\hline 1 & Luohe & 0.58 & 11 & 10 & Xuchang & 1.09 & 10 \\
2 & Luoyang & 2.01 & 3 & 11 & Jiyuan & 0.34 & 18 \\
3 & Anyang & 2.03 & 5 & 12 & Zhumadian & 1.51 & 17 \\
4 & Zhoukou & 2.83 & 16 & 13 & Nanyang & 3.62 & 13 \\
5 & Xinyang & 2.38 & 15 & 14 & Sanmenxia & 0.63 & 12 \\
6 & Puyang & 2.25 & 9 & 15 & Jiaozuo & 2.01 & 8 \\
7 & Xinxiang & 2.57 & 7 & 16 & Zhengzhou & 2.50 & 1 \\
8 & Hebi & 0.74 & 6 & 17 & Kaifeng & 2.81 & 2 \\
9 & Pingdingshan & 1.44 & 4 & 18 & Shangqiu & 2.20 & 14 \\
\hline
\end{tabular}




\section{Summary}

With the effect of water transfer plan, the situation of water scarcity in 15 years changes as well. In order to show the difference of situation without intervention and with intervention, we use the regression model again to predict the water scarcity in 15 years. We find that the water scarcity will still occur around 2031.

\section{References}

[1] Chen G. Time Series Analysis and Forecast of Annual Precipitation on Lasa Based on ARIMA Model [J][J]. Journal of North China Institute of Aerospace Engineering, 2011, 5: 007.

[2] Xiao-bin Y. Analysis about the Rainfall Condition During the Recent Ten Wet Seasons in Pudong New Area[J]. Water Sciences and Engineering Technology, 2012, 2: 005.

[3] Di L I U, Cailong H U, Zening W U. Predicting method for demand of agriculture water based on quantitative analysis[J]. Journal of Irrigation and Drainage, 2008, 27(6): 88-91.

[4] TONG C, Shi B H, LI H, et al. Water use variation trend and the forecast for the industrial water demand of Erdos City[J]. Journal of Arid Land Resources and Environment, 2011, 1: 030.

[5] XU C, FENG X. Spatial and Temporal Distribution of Rainfall Characteristics of Henan Province[J]. Journal of Anhui Agricultural Sciences, 2014, 25: 068.

[6] HU Z, DING C. Model for Resource Availability Prediction Based on Grey Model [J][J]. Journal of System Simulation, 2010, 3: 055.

[7] Xiang-yang L I. Genetic algorithm for VRP [J]. Computer Engineering and Design, 2004, 31(5): 271-276.

[8] Yan-fang N. Study on the Model and Algorithm for Vehicle Routing Problem [J][J]. Shanxi Electronic Technology, 2010, 1: 026.]

[9] http://www.stats.gov.cn/.

[10] http://www.unep.org/dewa/vitalwater/index.html 